points which refer to numbered stakes found at intervals along the route, which is marked out by arrows and signs. There may be displays giving further information about the important features of the environment. At Gibraltar Point Local Nature Reserve, in Lincolnshire, there is an information centre where voluntary wardens answer questions at the weekends.

At Alvecote Pools the National Coal Board has leased a disused Methodist chapel to the West Midlands Trust for Nature, and this has been equipped as a day centre, supervised by a committee of local teachers. It is used regularly by about twenty-five schools in the area. Nature trails are clearly very valuable as a supplement to biology lessons. The handbook points out that, although the trails are chiefly a teaching aid for younger children, they can help to illustrate and clarify examination syllabuses such as advanced level botany. Plant identification and taxonomy can certainly be made more real, but whether they can be taught painlessly, as the handbook claims, is less certain.

\section{A Catalogue of Earthquakes}

The International Seismological Centre in Edinburgh is beginning to fulfil what it sees as its main function, the publication of a regional catalogue of earthquakes. The centre, formed in 1963, last year issued its first regional catalogue, which listed earthquakes for the first six months of 1964. The catalogue is based on readings from a global network of 612 stations, and lists nearly 5,000 events thought to be earthquakes, arranged according to the geographical region in which they occurred. In addition, the catalogue contains details of 186 known or probable explosions, data which can be useful for the calibration of seismographs.

Computer processing of the raw data is essential for cataloguing work of this kind, but computer programmes are remarkably prone to teething troubles, and these seem to be the main reason for the $3 \frac{1}{2}$ year delay in publication. Some time lag is inevitable, it seems, because of the inaccessibility of many earthquake recording stations, and the time the data take to reach Edinburgh. Because the catalogue is intended to be a final record, replacing preliminary results published only months after the events, data from remote stations, some in the Antarctic, are included.

The director of the centre, Dr P. L. Willmore, is hoping to cut down the delay in publication to two years or eighteen months, now that the initial difficulties have been ironed out. Once the influx of data is under control and the catalogue brought up to date, the ISC expects to find time to analyse records from before 1964 and to produce catalogues of earthquakes occurring in the $1950 \mathrm{~s}$.

The most rapid publication of preliminary seismic observations and determinations of the epicentre of earthquakes is the province of the United States Coast and Geodetic Survey. These reports are especially useful to relief expeditions dispatched to assist at earthquake disasters where local lines of communication have been destroyed. In such cases, the times and locations at which shocks occurred can be invaluable.

On the other hand, catalogues like that produced by the International Seismological Centre find their main application in long-term statistical investigations of earthquakes. Designers of large-scale structures which are especially prone to earthquakes-dams and tall office blocks, for example-like to know how susceptible the area they are building in is to earthquakes. Here the regional catalogue of earthquakes will help.

\section{Skopje Earthquake}

AFTER the earthquake in Skopje on July 26, 1963, the government of Yugoslavia decided to investigate the causes and effects of the earthquake damage, so that the city could be rebuilt with better resistance to the stresses of any future earthquake. As well as calling in Yugoslavian scientists and engineers, the government sent a request to UNESCO for experts to advise them. The findings of these four investigators have now been published (UNESCO, 51s.).

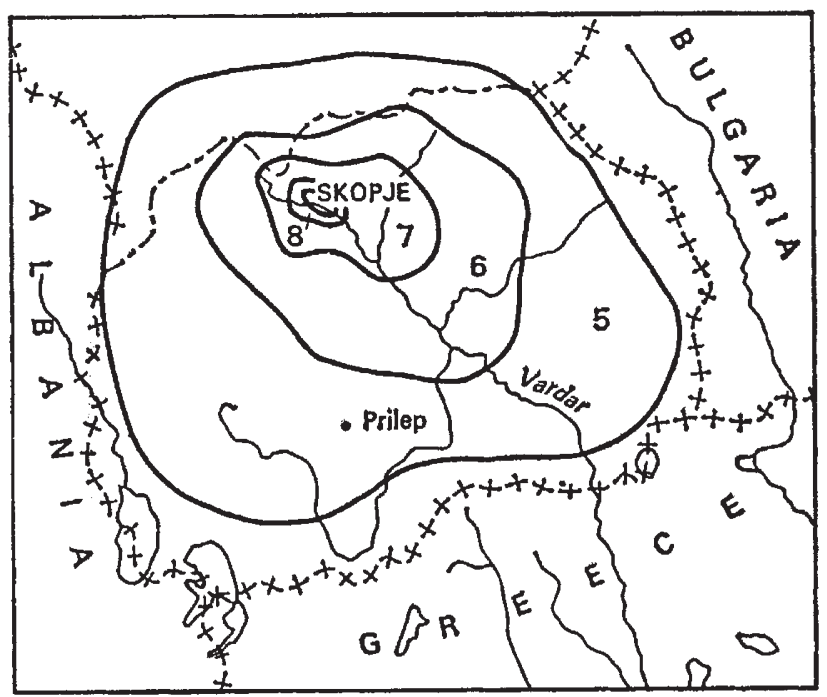

Distribution of observed intensities for earthquake on July 26, 1963 (compiled by D. Hadzievski and A. Zátopek).

Mr J. Despeyroux, chief engineer of SOCOTEC in Paris, reported on building problems and Dr N. N. Ambrayseys of Imperial College produced an engineer. ing seismology study of the earthquake. It was concluded that there would be no point in moving the city completely, but if new building developments are spread out around the city the risk will be minimized. In replanning the old city wide streets can be included to give good access to the centre. Special building codes for earthquake resistant structures are advisable, and controlled quality of structural materials, about which builders should be informed, would increase the safety of permanent buildings. Thirty per cent of the most important buildings in the city were left intact or were not irreparably damaged, those which were properly designed and constructed being the best survivors. Regulation of the River Vardar is important because it affects the seismic quality of the ground. Earthquake engineering and seismology are different, although related, subjects, and the former is neglected. Dr Ambrayseys suggests that a school should be set up in Skopje to train engineers and architects to postgraduate level in earthquake engineering, geotectonics 
and seismology. It would be the first of its kind in Europe.

Dr A. Zátopek from Czechoslovakia, an expert in seismology, assembled and analysed macro- and microseismic data with the conclusion that the epicentral intensity was IX MCS and the focal depth $5 \mathrm{~km}$ at Skopje, the epicentre. In all, the shaken area covered $105 \mathrm{~km}^{2}$. The earthquake was described in general terms as a superficial or shallow tectonic, composed of several shocks, with typical small block structure mechanism within the epicentral area. Dr Zátopek recommended that there should be detailed studies of the seismology of Yugoslavia.

The final part of the report was produced by Dr A. A. Sorsky of the University of Moscow, who studied the geological and tectonic factors of the 1963 earthquake. His conclusions include the fact that Skopje is on a seismologically dangerous area, and earthquakes are liable to occur there again. Seismological and geological data are being collected by Yugoslav scientists so that a microregionalization map can be compiled, from which can be worked out the areas of most movement and consequently most seismological danger. Provided building sites are chosen according to this map, Dr Sorsky believes that building should continue on the present site of the city.

\section{Keeping Physicists Aware}

CoMPARATIVELY recently there has emerged a new type of indexing journal, aimed at alerting readers quickly to titles of papers written in their respective fields. In their simplest form, current awarencss journals, as they are called, consist of a collection of facsimile reproductions of contents tables of individual journals. The weekly list, Current Contents, published by the Institute for Scientific Information, Philadelphia, since 1958 , is a well known example of a journal of this type. The Polish Academy of Sciences produces a similar key to the Polish literature. A more sophisticated example of a current title index is provided by the scmi-monthly Chemical Titles, a product of the Chemical Abstracts service, which is a computer produced keyword index.

In January 1966, the Institution of Electrical Engineers (IEE), in association with the American Institute of Physics (AIP), inaugurated a new current awareness journal called Current Papers in Physics to be used in conjunction with Physics Abstracts produced by the same institutions. The IEE also publishes two other current awareness journals, Current Papers on Control and Current Papers in Electrotechnology; and two other abstract journals, Control Abstracts and Electrical and Electronics Abstractstogether the journals are known as INSPEC (Information Service in Physics, Electrotechnology and Control).

It was decided, before Current Papers in Physics $(C P P)$ began publication, that it would be sensible to assess the need for this new journal and its usefulness. During its first year of publication (1966) a joint study was therefore undertaken in Britain by the Aslib Research Department for the IEE and in the United States by the then Documentation Research Project staff of AIP. The first report of this study has recently been published (Results of Questionnaire on Current Awareness Methods used by Physicists prior to Publication of "Current Papers in Physics").
Panels of physicists were set up in Britain (268 physicists) and the United States (682 physicists). Before $C P P$ appeared, the panel members received the first of a series of three tests. This initial questionnaire covered panel composition; methods used by physicists to keep up to date before $C P P$; and expectations of a current awareness journal in the field of physics. Results of this questionnaire are given in this report. Two later questionnaires covered physicists' comments on CPP and suggested improvements, and a record of the actual use made of the publication and the order in which sections were scanned. Reports of these studies are to be published later.

The results of the first survey show that current awareness journals were not much used by panel members before CPI' appeared. In general, the use tended to follow the pattern of the country of publication. The journals published in the UK--British Technology Index and Current Papers for the Professional Electrical and Electronics Engineer (now Current Papers in Electrotechnology) were more uscd in the UK than in the US, and the reverse was true for the US physicists in terms of Chemical Titles, Current Contents: Physical Sciences, for example. Physicists co-operating in the study seemed to rely mainly on scanning current issues of journals as a means of keeping up to date before $C P P$. It was thought to be the best method by 36 per cent of the British physicists, while 37 per cent of United States physicists ranked this method in first place. The physicists indicated, however, that they would welcome a publication that would relieve them of the chore of actually seanning journals, provided that "nothing relevant" was missed. There were various constructive suggestions about the requirements of a current awareness journal, and also comments about available abstract journals. The IEE must be satisfied with the discovery that Physics Abstracts was the most widely used publication in the field, in both Britain and the United States. As the report puts it, "the heavy usage of this existing IEE publication in physics augurs well for the success of a complementary current awareness journal from the same publishers". The next two reports may well show if this is indeed the case. At the moment the IEE appears to be satisfied with the sale of $C P P$ in Britain and in the United States.

\section{Fish Farming}

Fisu farming has been shown to be practicable, but the "rate at which the prospects are converted into reality will depend critically on the research effort we are able to mount". This was the conclusion of Dr H. A. Cole, Director of Fishery Research at Lowestoft, who addressed the Royal Society of Arts last week on the artificial cultivation of sea and shell fish and described the research which must be done bcfore a successful intensive rearing system can be built. There must be "systematic optimization of the environmental factors present in the system followed by scientific breeding to provide animals highly adapted to culture conditions".

The depletion of fish supplies accessible to British fishermen has led to the investigation of alternative sources, and to the realization that artificial cultivation can lead to advantages in processing and marketing, with possibilities for export. Plaice was one of the 